\title{
Measuring QT dispersion: man versus machine
}

\author{
Alan Murray, Neil B McLaughlin, Ronald W F Campbell
}

\begin{abstract}
Objective-To compare manual and computer automated techniques for measuring QT dispersion.

Design-Assessment of the ability of manual and automatic measurements of QT dispersion to discriminate between a normal group and two cardiac groups.

Subjects-12 simultaneous electrocardiogram leads were recorded from 25 healthy volunteers, 25 subjects after myocardial infarction, and 25 with cardiac arrhythmias.
\end{abstract}

Main outcome measures-For each subject, QT dispersion was measured as the difference between the maximum and minimum QT from all 12 leads and separately for only those leads with $T$ amplitudes of $>100 \mu \mathrm{V}$ and for those $>250 \mu \mathrm{V}$. Results-Manual QT dispersion (T > $100 \mu \mathrm{V})$ was greater $(\mathrm{P}<0.02)$ in the arrhythmia patients (mean (SD), 45 (21) $\mathrm{ms}$ ), but not the infarction patients (54 (36) $\mathrm{ms}$ ), than in the normal subjects (39 (13) $\mathrm{ms}$ ). There were no significant differences when all $T$ waves were included. $Q T$ dispersion was significantly reduced by an average of $30 \%$ when $\mathrm{T}$ waves $<100 \mu \mathrm{V}$ were excluded, and by $51 \%$ when those $<250 \mu \mathrm{V}$ were excluded. Automatic techniques gave different measurements for dispersion in comparison with manual measurements. Three of the four automatic techniques detected significant differences between normal and both patient groups when no leads were excluded $(P<$ $0 \cdot 01$ ) as well as when $T$ waves $<100 \mu \mathrm{V}$ were excluded (with increased significance, $P<0.002$ ).

Conclusions-Measurements of QT dispersion from small $T$ waves increases measurement variability and reduces the potential for detecting clinical differences. Automatic measurement of QT dispersion gives different results from manual measurement, but can satisfactorily discriminate between normal and abnormal groups with good quality electrocardiograms.

(Heart 1997;77:539-542)

Keywords: QT dispersion; repolarisation; computer analysis; ECG

Dispersion of the QT interval across the 12 standard electrocardiogram leads can provide valuable clinical information. Greater than normal levels of dispersion are associated with death, especially sudden death in heart failure, ${ }^{1}$ and with a poor prognosis in hypertrophic cardiomyopathy. ${ }^{2}$ In addition, increased dispersion has been associated with a risk of ventricular fibrillation in acute myocardial infarction $^{3}$ and with drug arrhythmogenesis. ${ }^{4}$

Traditionally, manual QT dispersion measurement has involved assessment and measurement of 12 leads of the electrocardiogram. This process is tedious and, as the end of $T$ is often ill defined, may be subject to human error. Reliable automatic measurement of QT dispersion is desirable. Although modern electrocardiograph recorders can measure the QT interval automatically, this is not always undertaken in all 12 leads and as yet there is no standardised algorithm for this measurement. Various different algorithms have been developed $^{56}$ for use in these recorders or for research. ${ }^{7-9}$ Earlier work from our group ${ }^{10}$ has shown that, because of the difficulty in identifying the end of the $T$ wave, different automatic techniques can result in widely different QT measurements from the same ECG complexes.

This study was designed to assess the effectiveness of automatic techniques for the measurement of QT dispersion, and to determine the effect of including or excluding measurements from small amplitude $T$ waves.

\section{Methods}

Our QT measurement methods have been described before, ${ }^{10}$ and are therefore presented in outline only.

DATA COLLECTION

All 12 leads of the electrocardiograms were sampled simultaneously by a computer with a resolution of $2.44 \mu \mathrm{V}$ at a sampling rate of $500 \mathrm{~Hz}$ for each lead channel. Electrocardiograms were obtained from 25 subjects in each of the following three groups: healthy volunteers with no history of heart disease, patients with myocardial infarction, and patients with known ventricular or supraventricular arrhythmias but excluding atrial fibrillation. Electrocardiograms were collected from as diverse a range of subjects as possible to ensure that a wide range of $T$ wave shapes was included.

\section{MANUAL ANALYSIS}

The electrocardiograms were plotted to paper using a laser printer with a resolution of 118
Tyne NE7 7DN, United

19 February 1997 
Figure 1 Manual measurement of $Q T$ dispersion for the three clinical groups, for all $T$ waves, and separately for $T$ waves $>100 \mu \mathrm{V}$. Values are means, error bars $=S D$. $\star P<0.02$.

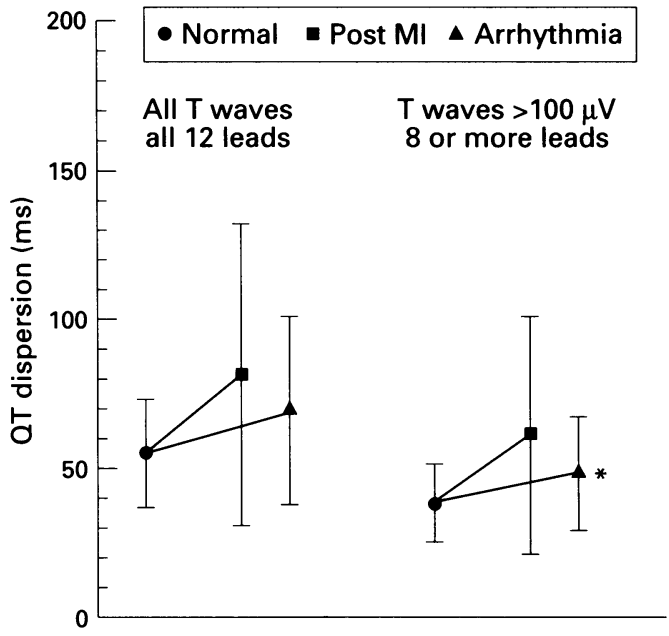

dots per $\mathrm{cm}$. The plots had a vertical (voltage) scale equivalent to $10 \mathrm{~mm} / \mathrm{mV}$ and a horizontal (time) scale equivalent to $50 \mathrm{~mm} / \mathrm{s}$. Using a digitising tablet and a previously validated technique, ${ }^{11}$ manual QT measurements were performed by an experienced researcher.

AUTOMATIC ANALYSIS

The stored electrocardiograms were filtered to a bandwidth of $0.05-40 \mathrm{~Hz}$ to reduce myopotential and electrical noise. Using computer software, the TP isoelectric level, amplitude of $\mathrm{T}$ wave, and maximum slope of the final com-

Table 1 Number of subjects available for the analysis of $Q T$ dispersion in the different subgroups

\begin{tabular}{|c|c|c|c|c|c|}
\hline \multirow[b]{2}{*}{$\begin{array}{l}\text { Clinical } \\
\text { group }\end{array}$} & \multicolumn{5}{|c|}{$T$ wave amplitude (number of leads) } \\
\hline & $\begin{array}{l}\text { All } \\
(12)\end{array}$ & $\begin{array}{l}>100 \mu \mathrm{V} \\
(4-12)\end{array}$ & $\begin{array}{l}>100 \mu \mathrm{V} \\
(8-12)\end{array}$ & $\begin{array}{l}>250 \mu \mathrm{V} \\
(4-12)\end{array}$ & $\begin{array}{l}>250 \mu \mathrm{V} \\
(8-12)\end{array}$ \\
\hline $\begin{array}{l}\text { Normal } \\
\text { Post-myocardial }\end{array}$ & 25 & 25 & 25 & 25 & 21 \\
\hline $\begin{array}{l}\text { infarction } \\
\text { Arrhythmia }\end{array}$ & $\begin{array}{l}25 \\
25\end{array}$ & $\begin{array}{l}23 \\
23\end{array}$ & $\begin{array}{l}14 \\
19\end{array}$ & $\begin{array}{l}13 \\
13\end{array}$ & $\begin{array}{l}4 \\
1\end{array}$ \\
\hline
\end{tabular}

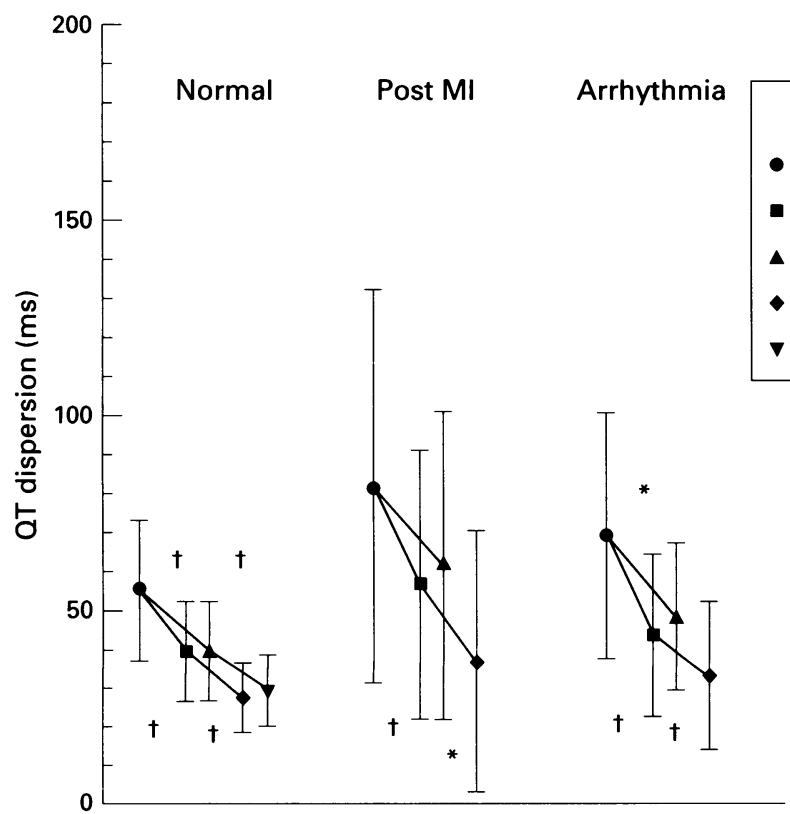

Figure 2 Manual measurement of $Q T$ dispersion for the three clinical groups for all $T$ waves, $T$ waves $>100 \mu \mathrm{V}$, and $\mathrm{T}$ waves $>250 \mu \mathrm{V}$, separately for all 12 leads, at least eight leads, and at least four leads. Values are means, error bars $=S D .{ }^{\star} P<0.05$; $+P<0.005$. ponent of the $T$ wave were determined. The $T$ wave end was determined by four techniques already described. ${ }^{10}$ Technique TH (threshold) and DTH (differential threshold) determined the $T$ wave end as the intersection of a threshold level with the $T$ wave and the differential of the $T$ wave respectively. The threshold levels were calculated as a fraction $(0 \cdot 1)$ of the amplitude of the $T$ wave or differential $T$ wave. Technique SI (slope intercept) identified the end of the $T$ wave as the intercept of the isoelectric line and a line tangential to the point of maximum $\mathrm{T}$ wave slope. Technique PSI (peak slope intercept) calculated the end of the $T$ wave as the intersection point between the isoelectric line and the line which passes through the peak of the $T$ wave and the point of maximum $T$ wave slope.

QT DISPERSION MEASUREMENT

QT was measured from two consecutive complexes in each electrocardiogram lead and the mean taken. Dispersion was defined as the difference between the maximum QT and the minimum QT across the 12 leads. Dispersion was then recalculated after excluding from analysis leads with $T$ wave amplitudes less than $100 \mu \mathrm{V}$, and then again with the exclusion of all leads with $T$ waves less than $250 \mu \mathrm{V}$. When $\mathrm{T}$ waves were excluded, dispersion measurements were calculated when there were at least eight leads remaining, and also when there were at least four leads remaining.

\section{DATA ANALYSIS}

The non-parametric Mann-Whitney test was used when making comparisons between groups. Whenever data could be paired, the paired differences were assessed using the signed Wilcox rank sum test. Data presented in the figures are shown as mean (SD).

\section{Results}

MANUAL MEASUREMENT

The results for the manual measurement of QT dispersion for all three clinical groups are shown in figure 1. Measurements are shown for all $T$ waves and separately for measurements from $\mathrm{T}$ waves which were more than $100 \mu \mathrm{V}$ in amplitude. When manual measurements were made in all 12 leads there were no significant differences between the patient groups. However, small $\mathrm{T}$ waves are known to introduce measurement variability. When $T$ waves of $100 \mu \mathrm{V}$ or less were excluded, significant differences between dispersion measures for the normal group (mean (SD), 39 (13) ms) and the arrhythmia group (45 (21) ms) were observed $(P<0.02)$. There was no significant difference between the normal and postmyocardial infarction groups (54 (36) ms, $P=0 \cdot 1)$, because of the very large range of measurements in the infarction group. The numbers of subjects in each subgroup are given in table 1 .

The effects of introducing different exclusion criteria for $T$ waves and requiring the availability of different minimum numbers of 


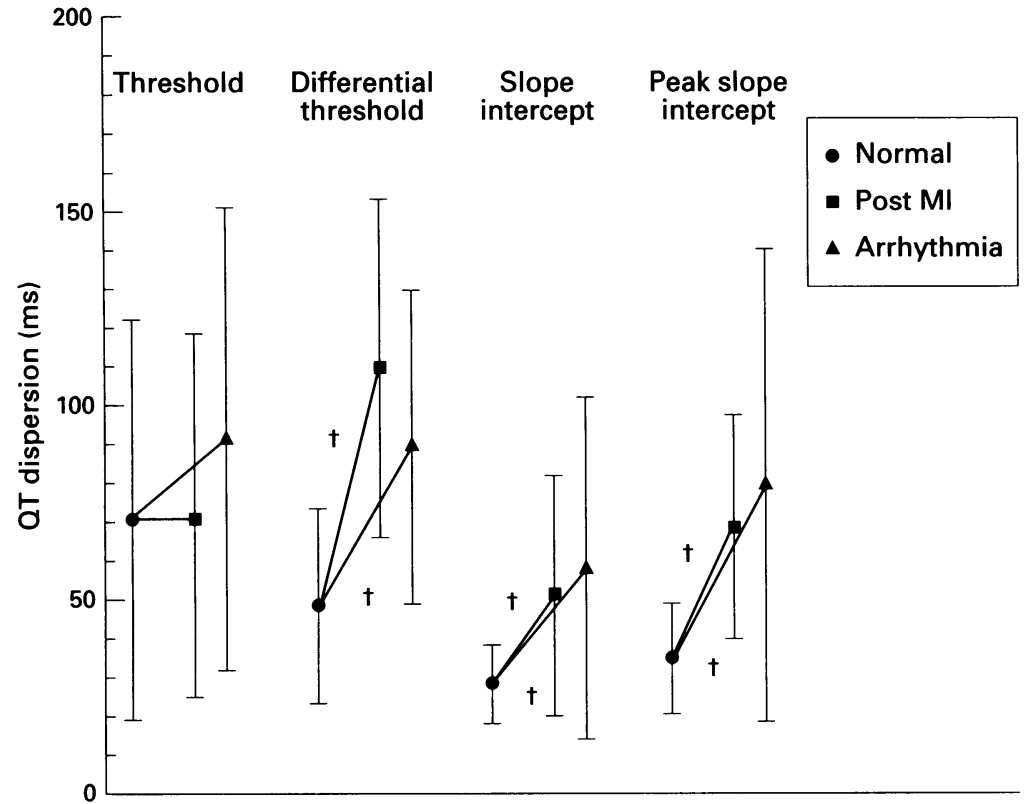

Figure 3 Automatic measurement of $Q T$ dispersion for the three clinical groups for all four automatic techniques studied for T waves $>100 \mu \mathrm{V}$ and at least eight leads available. There were very significant differences between the normal group and the other two groups for all techniques except the threshold technique. Values are means, error bars $=S D$. $+P<0.002$.

leads are shown in figure 2 . When small $\mathrm{T}$ waves were excluded there were significant reductions in QT dispersion. Across all subject groups there was an average fall of $30 \%$ when $\mathrm{T}$ waves with an amplitude of $<100 \mu \mathrm{V}$ were excluded, and by $51 \%$ when those $<250 \mu \mathrm{V}$ were excluded. There were no significant differences between measurements which included at least eight leads and those which included at least four leads.

\section{AUTOMATIC MEASUREMENT}

Figure 3 shows the automatic measurements of QT dispersion for the three clinical groups for $T$ waves of $>100 \mu \mathrm{V}$ when at least eight leads were available. All automatic techniques except the threshold technique showed very significant differences between the normal subjects and the two patient groups $(P<0.002)$.

\section{COMPARISON BETWEEN MANUAL AND}

AUTOMATIC MEASUREMENT

Figure 4 plots the differences between the manual and automatic dispersion measurements for the same data as in fig 3 ( $T$ waves of $>100 \mu \mathrm{V}$ and at least eight leads). The mean (SD) of these paired differences are tabulated, along with the other intercomparisons, in table 2 .

Table 2 Mean (SD) of paired difference in dispersion between the measuremen techniques for all groups with $T$ waves at least $100 \mu \mathrm{V}$ in at least eight leads. Data are given for the measurement indicated at the left of each row minus the data indicated at the top of each column

\begin{tabular}{|c|c|c|c|c|}
\hline & \multicolumn{4}{|c|}{ Mean (SD) dispersion difference (ms) } \\
\hline & $\begin{array}{l}\text { Differential } \\
\text { threshold }\end{array}$ & $\begin{array}{l}\text { Slope } \\
\text { intersection }\end{array}$ & $\begin{array}{l}\text { Peak slope } \\
\text { intersection }\end{array}$ & Manual \\
\hline $\begin{array}{l}\text { Threshold } \\
\text { Differential threshold } \\
\text { Slope intersection } \\
\text { Peak slope intersection }\end{array}$ & $1(62)$ & $\begin{array}{l}34(53) \dagger \\
34(42) \dagger\end{array}$ & $\begin{array}{r}19(56)^{\star} \\
19(47)^{\star} \\
-15(21) \dagger\end{array}$ & $\begin{aligned} 30(53) \dagger \\
29(36) \dagger \\
-4(34) \\
10(42)\end{aligned}$ \\
\hline
\end{tabular}
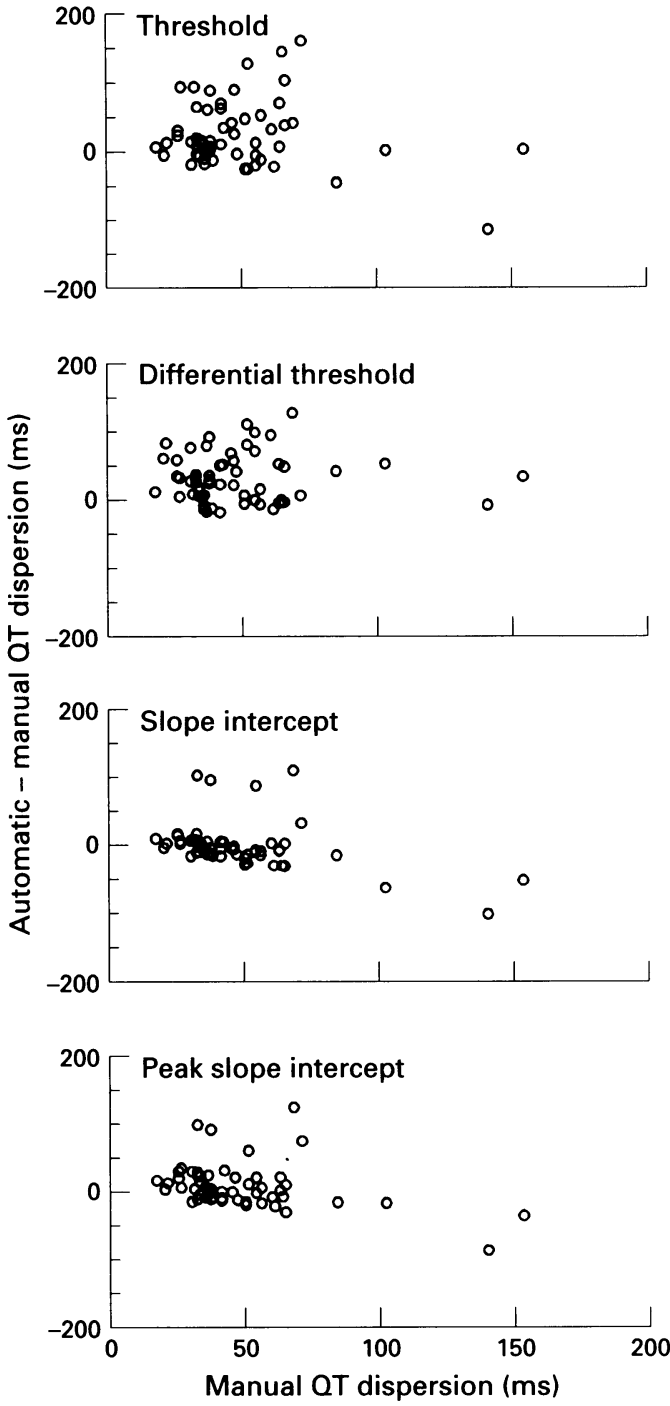

Figure 4 Difference between automatic and manual measurements of $Q T$ dispersion, for ECGs from all groups with the $T$ wave at least $100 \mu \mathrm{V}$ in at least eight leads. Data are given for the four automatic techniques.

\section{Discussion}

When the three groups were compared using manual measurements from all 12 leads no significant differences were detected. However, small $\mathrm{T}$ waves are known to introduce greater variability in measurement. ${ }^{12}$ When these were excluded, QT dispersion was significantly greater in the arrhythmia patients than in the normal subjects. Although the mean dispersion in the infarct group tended to be greater (not significantly), there were no significant differences between the normal and infarct group because of the large range of dispersion values. These reflect the range of dispersion, but may also be influenced by measurement difficulties with more diverse $T$ wave shapes.

We have previously suggested that accurate QT measurement demands a $\mathrm{T}$ wave amplitude of at least $250 \mu \mathrm{V} .{ }^{12}$ However, excluding small $\mathrm{T}$ waves may jeopardise the reliability of QT dispersion analysis. The selection of such a threshold level is therefore a compromise between excluding too many small $T$ waves and maximising the number of leads available for analysis. From the results obtained, 
$100 \mu \mathrm{V}$ is a reasonable compromise for dispersion analysis.

The number of leads available for analysis is important. For the main analysis of this study we required at least eight measurable leads. Nevertheless, including results from four or more leads had a smaller effect on QT dispersion than in changing the amplitude threshold for $T$ wave inclusion. This was particularly evident in the post-myocardial infarction group. Including all $\mathrm{T}$ waves of $>100 \mu \mathrm{V}$, there were 23 patients with at least four leads available for analysis and 14 with at least eight leads, but there was no significant difference in QT dispersion between the four and eight lead data. Currently there are different views on the validity of correcting or adjusting QT dispersion for missing leads. Hnatkova et $a l^{13}$ accepted that correction was difficult, but concluded that the formula used in their study could be used to adjust QT in healthy subjects. Our study was not designed to determine whether a correction should be applied to compensate for missing leads, but it highlights the considerable problems that a correction factor would introduce. This is supported by Glancy et al ${ }^{14}$ who concluded that lead adjustment formulas for QT dispersion are not appropriate in patients with myocardial infarction. In clinical QT dispersion studies $T$ waves are often excluded because they were small or difficult to measure. As they were not randomly selected, the statistical rules for correcting random sample data cannot be applied.

Our data provide strong support for the view that QT dispersion can be measured automatically, albeit with a different range of values. QT measurement based on intersection of the $T$ wave with a threshold level above the isoelectric level, however, cannot be recommended. This accords with our previous work showing that variability using this technique was unacceptably high. ${ }^{10}$ The three other techniques gave discriminating results, and in that respect were superior to manual measurement. As in our study all electrocardiograms were of good quality, it is possible that as noise increases some or all of these techniques would suffer in comparison with manual measurement.

A normal range of QT dispersion is as yet to be defined, but it will be very dependent on the assessment technique employed. We have shown that, with certain limits, automatic QT dispersion analysis can be powerful, but whatever technique is finally adopted, it must be described accurately. Different techniques will produce different dispersion results, and new reference ranges will need to be adopted.

Our findings that the QT measurement approach based on the slope intercept technique can give useful results indicates that information on dispersion is contained not just in the final components at the end of the $T$ wave, but also on other aspects of the $T$ wave. This raises the prospects of capturing even more information from the surface electrocardiogram $T$ wave. This observation is important for improving our understanding of the electrophysiological factors influencing QT dispersion.

\section{CONCLUSION}

QT dispersion can be assessed automatically in electrocardiograms of good quality. Small amplitude $T$ waves pose a particular problem and we would recommend that those smaller than $100 \mu \mathrm{V}$ are not used. Our results suggest that the $T$ wave may contain more information than is currently addressed even by the relatively new approach of QT dispersion. Recovering QT and $\mathrm{T}$ wave information is very dependent on ECG quality. Studies and clinical assessments based on these features must employ meticulous methods to acquire the electrocardiogram and hence maximise the opportunities for analysis. In addition, we have shown that global features of $\mathrm{T}$ waves provide valuable information on dispersion, and this should help to improve our understanding of the clinical source of QT dispersion.

This work was supported by the British Heart Foundation. Mrs C Moore assisted with collection and analysis of electrocardiograms used in this study.

1 Barr CS, Naas A, Freeman M, Lang CC, Struthers AD. QT dispersion and sudden unexpected death in chronic heart failure. Lancet 1994;343:327-9.

2 Buja G, Miorelli M, Turrini P, Melacini P, Nava A. Comparison of QT dispersion in hypertrophic cardiomyopathy between patients with and without ventricular arrhythmias and sudden death. Am 7 Cardiol 1993;72: 973-6.

3 Higham J, Furniss SS, Campbell RWF. QT dispersion and components of the QT interval in ischaemia and infarction. Br Heart f 1995;73:32-6.

4 Hii JTY, Wyse DG, Gillis AM, Duff HJ, Solylo MA, Mitchell LB. Precordial QT interval dispersion as a marker of torsade de pointes. Disparate effects of class 1a antiarrhythmic drugs amiodarone. Circulation 1992;86: 1376-82.

5 Laguna P, Thakor NV, Caminal P, Jane R, Yoon H-R, Bayes de Luna A, et al. New algorithm for QT interval analysis in 24-hour Holter ECG: performance and applianalysis in 24-hour Holter ECG: performance

6 Algra A, le Brun H, Zeelenberg C. An algorithm for computer measurement of QT intervals in the 24 hour ECG. In: Computers in Cardiology 1986. Los Alamitos: IEEE Computer Society Press, 1987:117-19.

7 Merri M, Benhorin J, Alberti M, Locati E, Moss AJ. Electrocardiographic quantitation of ventricular repolarization. Circulation 1989;80:1301-8.

8 Mirvis DM. Spatial variation of QT intervals in normal persons and patients with acute myocardial infarction. $\mathcal{f}$ Am Coll Cardiol 1985:5:625-31.

9 O'Donnell J, Lovelace E, Knoebel SB, McHenry PL. Behavior of the terminal $\mathrm{T}$-wave during exercise in normal subjects, patients with symptomatic coronary artery disease and apparently healthy subjects with abnorm ST segment depression. 7 Am Coll Cardiol $1985 ; 5: 78-84$.

ST segment depression. F Am Coll Cardiol 1985;5:78-84. of automatic QT measurement techniques in the normal of automatic QT measurement techniques in the norm
12 lead electrocardiogram. Br Heart $\mathcal{F} 1995 ; 74: 84-9$.

11 Murray A, McLaughlin NB, Bourke JP, Doig JC, Furniss SS, Campbell RWF. Errors in manual measurement of ST, Campbell RWF. Errors in manual mearts. Br Heart f 1994;71:386-90.

12 McLaughlin NB, Campbell RWF, Murray A. Accuracy of four automatic QT measurement techniques in cardiac four automatic QT measurement techniques in card

13 Hnatkova K, Malik M, Kautzner J, Gang Y, Camm AJ. Adjustment of QT dispersion assessed from 12 lead electrocardiograms for different numbers of analysed electrocardiographic leads: comparison of stability of different methods. Br Heart $\mathcal{F}$ 1994;72:390-6.

14 Glancy JM, Garratt CJ, Woods KL, de Bono DP. Use of lead adjustment formulas for QT dispersion after myocardial infarction. Br Heart $\mathcal{f}$ 1995;74:676-9. 